Avalaible online: https://ejournal.iai-tribakti.ac.id/index.php/pgmı

Article doi: https://doi.org/10.33367/jiee.v3i1.1560

Submission: 2021-1-30 Review: 2021-3-2 Revision: 2021-3-2 Accepted: 2021-3-2

\title{
Upaya Pengintegrasian Living Values Education (LVE) dalam Proses Pembelajaran IPA Siswa Kelas IV di MI Tunas Cendekia Cirebon
}

\section{Efforts to Integrate Living Values Education (LVE) in the Science Learning Process IPA Class IV in Tunas Cendekia Cirebon Elementary School}

\author{
Suci Muzfirah' ${ }^{1}$ Muqowim $^{2}$ \\ 1 UIN Sunan Kalijaga Yogyakarta, ${ }^{2}$ UIN Sunan Kalijaga Yogyakarta \\ 119204080044@student.uin-suka.ac.id ; ${ }^{2}$ muqowim@uin-suka.ac.id
}

\begin{abstract}
One of the problems in every learning process is the lack of life values for students, especially in science learning. The values of life or living values education are very important to be given to students so that the school can produce graduates who are not only superior in academia and cognitive, but in rustakter education and living values education (LVE). In this context, it is very important to review efforts to integrate living values education in the learning process of science grade IV at MI Tunas Cendekia Cirebon. In order to get the results of the research, the method carried out by researchers is a descriptive qualitative method. The resulting data source is the result of observation, interview, and documentation analysis. The entire data is processed and processed to be presented as a result of the research. The results showed that efforts to integrate living values education (LVE) in the learning process of science students in grade IV at MI Tunas Cendekia Cirebon are students able to understand the values of life and will affect the development of student character. Integration of Islamic education through living values education can also be done so that students can learn Islamic values in the process of science learning through living values education.
\end{abstract}

Key Word: Integration, Living Values Education, Science Learning

\begin{abstract}
Abstrak
Salah satu permasalahan pada setiap proses pembelajaran adalah kurangnya pemberian nilai-nilai kehidupan bagi siswa, khususnya pada pembelajaran IPA. Nilai-nilai kehidupan atau living values education sangat penting untuk diberikan kepada siswa agar sekolah dapat menghasilkan lulusan yang tidak hanya unggul di bidang akademisi dan kognitif, tetapi dalam pendidikan karatakter dan living values education (LVE). Dalam konteks inilah, sangat penting untuk mengkaji upaya pengintegrasian living values education dalam proses pembelajaran IPA kelas IV di MI Tunas Cendekia Cirebon. Agar mendapatkan hasil penelitian, metode yang dilakukan oleh peneliti adalah metode kualitatif deskriptif. Sumber data yang dihasilkan adalah hasil pengamatan, wawancara, dan analisis dokumentasi. Keseluruhan data diolah dan diredukasi untuk dipaparkan sebagai hasil dari penelitian. Hasil
\end{abstract}


penelitian menunjukan, upaya pengintegrasian living values education (LVE) dalam proses pembelajaran IPA siswa kelas IV di MI Tunas Cendekia Cirebon adalah siswa mampu memahami nilai-nilai kehidupan dan akan berpengaruh pada perkembangan karakter siswa. Pengintegrasian pendidikan keislaman melalui living values education juga dapat dilakukan sehingga siswa dapat mempelajari nilai-nilai keislaman dalam proses pembelajaran IPA melalui living values education.

Kata Kunci: Integrasi, Living Values Education, Pembelajaran IPA

\section{Pendahuluan}

Pendidikan ialah suatu hak setiap peserta didik. Pada pembukaan UUD, pendidikan menerima perhatian spesifik dan tercantum secara eksplisit pada Alinea keempat. Bahkan Pendidikan telah diklaim sebagai sebuah hak asasi yang harus secarabebas dapat dimiliki oleh seluruh anak ${ }^{1}$. Pada Undang-Undang No. 20, Tahun 2003 Pasal 3 menyebutkan bahwa Pendidikan Nasional berfungsi untuk mengembangkan kemampuan dan membentuk watak serta peradaban bangsa yang bermartabat.

Pendidikan pada jenjang anak usia 6-12 tahun ada pada jenjang sekolah dasar (SD/MI). Salah satu proses pembelajaran yang wajib diajarkan kepada anak ialah pembelajaran IPA. IPA ialah rumpun ilmu, mempunyai karakteristik spesifik yakni mengkaji fenomena alam yang sebenarnya (factual), baik berupa kenyataan (reality) atau peristiwa (events) dan korelasi sebab akibatnya. Pendidikan IPA atau pendidikan sains pada jenjang sekolah atau madrasah mestinya bisa memberikan bekal kepada peserta didik agar mereka bisa hidup selaras

${ }^{1}$ eka sulistyowati wisudawati asih widi, Metodologi Pembelajaran IPA (Jakarta: Bumi Aksara, 2015), h. 1. el Bidayah: Journal of Islamic Elementary Education Volume 3, Nomor 1, Maret 2021 sesuai dengan perkembangan zaman. Dengan adanya hal tersebut, maka seluruh kaum pendidik perlu selalu berusaha untuk tetap menata proses pembelajaran dan bahan serta materi ajar yang tersaji agar terwujudnya insan-insan Indonesia yang sesuai dengan tujuan pendidikan nasional. Pada taraf Sekolah Dasar (SD) atau Madrasah Ibtidaiyah (MI) pola pemikiran peserta didik tentang suatu pengetahuan akan terbawa terus ke tingkat atau jenjang yang lebih tinggi. Hal ini dikarenakan pada taraf SD/MI, kawasan dasar ilmu disampaikan kepada peserta didik khususnya pada mata pelajaran IPA. Pembelajaran IPA sebagai salah satu komponen krusial dalam pendidikan acapkali menjadi bahan kritikan dari berbagai kalangan mengingat hasil belajar yang didapatkan peserta didik SD/MI untuk mata pelajaran IPA cenderung rendah bila dibandingkan dengan mata pelajaran lainnya. Dengan adanya hal tersebut maka mengakibatkan kualitas dari pembelajaran IPA terus menerus dituduh bersalah dan menjadi penyebab utama dari rendahnya prestasi belajar para peserta didik khususnya pada mata pelajaran IPA di SD/MI. ${ }^{2}$

\footnotetext{
2 'PENGEMBANGAN MEDIA PEMBELAJARAN IPA BERBASIS ANDROID UNTUK SISWA SD/MI
} 
Prinsip proses pembelajaran ialah belajar, sedangkan belajar ialah suatu proses perubahan sikap individu yang relative permanen yang menjadi hasil dari sebuah pengalaman. Oleh sebab itu, pembelajaran merupakan upaya penataan lingkungan yang kondusif, sehingga proses belajar bisa tumbuh serta berkembang ${ }^{3}$. Pembelajaran IPA adalah korelasi antar berbagai macam komponen pembelajaran dalam bentuk proses belajar mengajar agar dapat mencapai tujuan yang berbentuk kompetensi yang telah ditetapkan sebelumnya. Proses pembelajaran IPA di sekolah secara keseluruhan dipengaruhi oleh beberapa hal, salah satunya ialah nilai-nilai yang akan menghasilkan kepribadian dan karakteristik peserta didik menjadi dampak pendamping (nurturant effect) serta dampak instruksi (instructional effect) dalam pembelajaran IPA.

Penelitian yang telah dilakukan menunjukkan bahwa tiap-tiap anak dari berbagai penjuru negara dan dengan beragam budaya yang tidak sama ternyata mempunyai kesamaan dalam melihat konsep-konsep IPA. Tenyata, konsep IPA tersebut tidak terkait dengan kebudayaan setempat melainkan dibuat oleh berbagai macam pengalaman langsung peserta didik saat bertautan dengan fenomena-fenomena yang ada disekitarnya. Pada hal ini Driver, et al. berkata bahwa "children's

Prasetyo | JMIE (Journal of Madrasah Ibtidaiyah Education)', n.d., 122, https://e-

journal.adpgmiindonesia.com/index.php/jmie/arti cle/view/29/9.

${ }^{3}$ Wahidin Wahidin, Metode Pendidikan IImu Pengetahuan Alam (Bandung: Sangga Buana, 2006), 22.

34 science conceptions are not idiosyncratic, nor are they in many cases heavily culturally dependent. They are shaped but personal experience with phenomena". Dengan hal demikian, tantangan pertama pembelajaran IPA pada sekolah dan madrasah ialah memberikan akses kepada peserta didik terhadap beragam pengalaman yang dialaminya serta membantu peseta didik untuk mengkonstruksi konsepkonsep IPA mereka seorang diri, dan mengenalkan berbagai konsep yang telah disepakati oleh masyarakat sains sebelumnya ${ }^{4}$.

Dalam bahasa sederhananya, kata integrasi berasal dari kata kerja berbahasa Inggris to integrate yang artinya ialah "menggabungkan pada sesuatu yang lain sehingga terciptalah keterpaduan atau keseluruhan"5. Integrasi nilai dalam pembelajaran atau pendidikan adalah proses bimbingan melalui suri tauladan pendidikan yang berorientasikan terhadap penanaman nilai-nilai kehidupan yang didalamnya mencakup nilai-nilai kepercayaan, kebudayaan, etika serta keindahan menuju pembentukan peserta didik yang memiliki kecerdasan spiritual keagamaan, pengendalian diri, kepribadian yang utuh, berakhlak mulia, dan keterampilan yang diperlukan dirinya, masyarakat serta negara6. Adapun integrasi nilai menurut Mardiatmadja

\footnotetext{
${ }^{4}$ wisudawati asih widi, Metodologi Pembelajaran IPA, 8.

5 'Pembiasaan Keterampilan Berpikir Kritis Sebagai Sarana Implementasi Sikap Spiritual Dalam Pembelajaran IPA Tingkat Sekolah Dasar | Kamala | Al-Bidayah: Jurnal Pendidikan Dasar Islam', n.d., 12 , https://jurnal.albidayah.id/index.php/home/articl e/view/187/173.

${ }^{6}$ Novianti, 'INTEGRASI NILAI-NILAI ISLAM DALAM PEMBELAJARAN IPA DI SEKOLAH | Muspiroh | QUALITY', 2014, 172, https://journal.iainkudus.ac.id/index.php/Quality/ article/view/2099/1737.
}

el Bidayah: Journal of Islamic Elementary Education Volume 3, Nomor 1, Maret 2021 
Oleh: Suci Muzfirah dan Muqowim

pada pendidikan sebagai bantuan kepada peserta didik supaya menyadari serta mengalami nilai-nilai dan menempatkannya secara integral pada keseluruhan hidupnya. Dalam hal ini pendidikan nilai tidak hanya merupakan suatu program spesifik yang diajarkan melalui sejumlah mata pelajaran, namun meliputi pula keseluruhan dari proses pendidikan. Pada hal ini pula, yang menanamkan nilai pada peserta didik bukan saja pengajar pendidikan nilai dan moral serta bukan saja pada waktu mengajarkannya, melainkan kapan saja dan dimana saja, nilai wajib menjadi bagian integral pada kehidupan peserta didik. Pengenalan tersebut sebaiknya diperkenalkan sejak usia anak-anak, yaitu pada usia 6-12 tahun, dikarenakan pada usia tersebut mereka secara alamiah mempunyai rasa ingin tahu yang sangat kuat serta merekapun tertarik akan dunia sekitar yang mengelilingi mereka sendiri; mereka selalu senang dalam melakukan berbagai macam permainan dan lebih suka untuk selalu bergembira; mereka juga sangat senang mengatur dirinya untuk menangani beraneka macam hal, mengeksplorasi suatu situasi serta mencobakan hal-hal baru yang belum pernah mereka rasakan; mereka mampu tergetar perasaannya dan terdorong untuk berprestasi sebagaimana mereka mengalami ketidak puasan dan menolak dari kegagalankegagalan; mereka akan belajar secara efektif saat mereka merasa puas dengan situasi yang telah terjadi; mereka belajar dengan cara bekerja, mengobservasi, berinisiatif serta akan mengajar anak yang lainnya yang belum bisa ${ }^{7}$.

\footnotetext{
${ }^{7}$ Rahayu Sulistiowati, Eko Budi Sulistio, and Ita Prihantika, 'PELATIHAN PENDIDIKAN INTEGRITAS UNTUK GURU SMP MELALUI METODE LIVING VALUES EDUCATION (LVE) DI KECAMATAN

Living values education (LVE) ialah pendidikan nilai kehidupan, dimana pendidikan tersebut secara resmi dibuat oleh PBB melalui conference UNICEF. Secara konkret, penanaman living values education (LVE) dihidupkan semangatnya melalui proses pembelajaran di sekolah, diintegrasi-interkoneksikan dengan berbagai macam pembelajaran. Living Values Education (LVE) ialah program pendidikan untuk membantu serta menyediakan kesempatan bagi tiap-tiap anak dan orang muda untuk menggali serta mengembangkan nilai-nilai universal dan juga berlanjut sampai mengasosiasikan nilai tersebut pada keterampilan sosial-emosional dan intrapersonal-interpersonal mereka dalam kehidupan sehari-hari ${ }^{8}$. Living Values Education (LVE) adalah aktivitas pengajaran berbagai nilai-nilai kehidupan melalui kegiatan-kegiatan dilihat berdasarkan nilai. Kegiatankegiatan didesain untuk memo-tivasi peserta didik serta mengajak mereka untuk memikirkan baik dirinya sendiri, orang lain, dunia, maupun nilai-nilai dalam cara yang tentunya saling berhubungan. Aktivitas-aktivitas tersebut memiliki tujuan untuk mencicipi pengalaman di dalam diri sendiri dan untuk membangun sumber daya diri. Aktivitas-aktivitas tersebut pula bertujuan untuk memperkuat serta memancing potensi, kreativitas, dan bermacam bakat yang dimiliki oleh tiap peserta didik. Para peserta didik diajak untuk dapat melakukan refleksi, imajinasi, mampu melakukan dialog, berkomunikasi dengan baik, meningkatkan kreativitas, membuat goresan pena, menyatakan diri lewat seni, serta

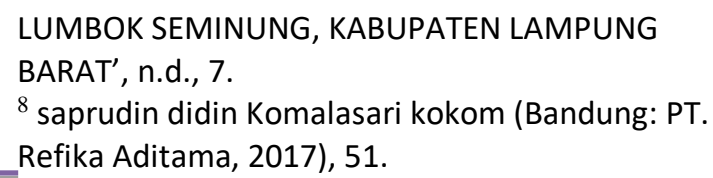


Oleh: Suci Muzfirah dan Muqowim

bermain-main dengan nilai-nilai yang telah diajarkan. Pada prosesnya, akan berkembang keteram-pilan pribadi, sosial, dan emosional, sejalan dengan keterampilan sosial yang tenang serta penuh kolaborasi dengan orang lain. Nilai-nilai ini telah disusun sedemikian rupa sehingga menyediakan serangkaian keterampilan yang dibangun satu di atas yang lain ${ }^{9}$.

Pengajaran literatur anak-anak yang mengintegrasikan karakter nilai dalam metode LVE dilakukan berdasarkan pendekatan pendidikan yang komprehensif. Ada empat tema nilai yang diinternalisasikan kepada siswa. Ialah seperti kepercayaan, ketaatan, tanggung jawab, cinta dan kasih sayang, serta kolaborasi. Keempat tema tersebut terintegrasi dengan keterampilan mendengarkan, berbicara, menulis, serta membaca. Keempat keterampilan bahasa tersebut dapat diuraikan pada materi sastra anak yang terintegrasi dengan materi pembelajaran sains, yang terdiri dari cerita, puisi, dan drama. Untuk mengukur prestasi pada keterampilan kognitif, afektif serta psikomotor, penulis menggunakan evaluasi terpadu pada kategori tes literariness yang berfokus pada konsep, perspektif dan taraf apresiasi ${ }^{10}$, sedangkan untuk kategori penanaman karakter yakni menggunakan program

\footnotetext{
${ }^{9}$ Hayati Nufus, 'PEMBINAAN KARAKTER MAHASISWA BERBASIS LIVING VALUES EDUCATION', al-Iltizam: Jurnal Pendidikan Agama Islam 4, no. 1 (30 May 2019): h. 155, https://doi.org/10.33477/alt.v4i1.758.

${ }^{10}$ Muh Arafik, 'Living Values Educational Program: Children Literature Instruction to Improve Character Values of Elementary School Students':, in Proceedings of the 1 St International Conference on Information Technology and Education (ICITE 2020) (1st International Conference on Information Technology and Education (ICITE 2020), Malang, Indonesia: Atlantis Press, 2020), h. 230, https://doi.org/10.2991/assehr.k.201214.241. 36
}

living values education. Membaca literatur anak juga mampu meningkatkan kesadaran siswa akan moral, nilai etika dan aspek lain yang tidak mereka pahami seperti mengembangkan empati dan semangat, perilaku berjasa. Ini juga membangkitkan kepekaan siswa terhadap aspek sosial, budaya dan ekonomi orang lain di dunia. Living values merupakan prinsip dan keyakinan yang mempengaruhi cara hidup dan perilaku setiap orang di linkungan masyarakat. Nilainilai ini didefinisikan untuk menentukan karakteristik individu dalam dimensi fisik, intelektual, sosialemosional, dan spiritual ${ }^{11}$. Untuk itu, penanaman karakter yang wajib diberikan pada siswa dapat menggunakan living values education programs agar tujuan pendidikan dan pembelajaran dapat tercapai sebagaimana mestinya.

Ilmu pengetahuan sains (IPA) di jenjang SD/MI berfungsi menjadi wadah bagi peserta didik untuk mengetahui dan mengkaji perihal diri sendiri dan linkungan alam serta dapat mengembanhkan dan menerapkan nilai-nilai tersebut dengan baik dalam kehidupan sehari-sehari ${ }^{12}$. Proses belajar mengajar dalam pem-belajaran IPA yang bermakna, diharapkan bisa meningkatkan kualitas Pendidikan pada jenjang SD/MI khususnya di Negara Indonesia. Adanya hal tersebut ternyata

\footnotetext{
${ }^{11}$ S Sarah, Z K Prasetyo, and I Wilujeng, 'Integration of Living Values into Physics Learning Based on Local Potentials', Journal of Physics: Conference Series 1022 (May 2018): 1, https://doi.org/10.1088/17426596/1022/1/012026.

${ }^{12}$ Fajrul 'Arofah, 'PEMBELAJARAN IPA DAN IPS BERBASIS INTEGRASI DAN INTERKONEKSI DENGAN PAI (STUDI KASUS DI MIN MLANGEN SALAMAN DAN MI MA"ARIF KEBONSARI BOROBUDUR KABUPATEN MAGELANG TAHUN PELAJARAN 2013/2014)' (Salatiga, Jawa Tengah, IAIN SALATIGA, 2015), 32.
}

el Bidayah: Journal of Islamic Elementary Education Volume 3, Nomor 1, Maret 2021 
Oleh: Suci Muzfirah dan Muqowim

sesuai dengan fakta yang ada dilapangan, bahwa proses pembelajaran IPA masih berorientasi kepada hasil (result oriented). Proses pembelajaran IPA ternyata belum menyentuh pada ranah nilai-nilai kebermaknaan dari konsep yang diperoleh di sekolah. Dengan menggunkaan konsep belajar mengajar yang bermakna pada proses pembelajaran IPA diharapkan akan mampu menjawab konflik yang dijumpai seorang peserta didik. Agar tujuan pembelajaran dan pendidikan di MI Tunas Cendekia Kabupaten Cirebon dapat dilaksanakan dengan baik, maka guru-guru berupaya untuk meng-integrasikan living values education dalam proses pembelajaran. Di kelas IV, walikelas mencoba mengupayakan pengintegrasian living values education dalam proses pembelajaran IPA.

\section{Metode}

Metode yang digunakan oleh peneliti ialah metode kualitatif. Peneliti juga menggunakan pendekatan kualitatif naratif atau deskriptif dalam proses penelitian. Adapun sumber data yang diambil oleh peneliti ialah walikelas IV dan peserta didik kelas IV di MI Tunas Cendekia Kabupaten Cirebon. Peneliti menggunakan 3 teknik pengumpulan data, yakni menggunakan teknik wawancara tidak tersrtuktur, observasi dan juga analisis dokumen. Seluruhnya dilakukan pada bulan Desember 2020 sampai Januari 2021 di Madrasah Ibtidaiyah Tunas Cendekia Kabupaten Cirebon. Peneliti memiliki prinsip dasar pada penelitian ini ialah kekuatan peneliti pada proses menafsirkan berbagai fenomena yang diteliti. Sebab itu, peneliti secara khusus meneliti pada proses pembelajaran IPA kelas IV MI Tunas Cendekia Cirebon. Adapun peneliti melihat adakah upaya pengintegrasian living values education dalam proses pembelajaran IPA pada kelas IV di MI Tunas Cendekia Kabupaten Cirebon.

\section{Temuan dan Pembahasan Temuan penelitian}

Dari hasil penelitian yang dilakukan oleh peneliti sesuai dengan data dilapangan yakni di MI Tunas Cendekia Cirebon. Maka diperoleh hasil bahwa guru sangat mengupayakan pengintegrasian living values education pada proses pembelajaran di seluruh kelas khususnya pada pembelajaran IPA kelas IV. Pembelajaran IPA di kelas IV mulai memasuki pembelajaran yang bersifat abstrak, tidak konkrit lagi seperti dikelas bawah. Maka proses penanaman nilai-nilai karakter sangat dibutuhkan oleh peserta didik. Saat melakukan observasi, dapat disimpulkan bahwa terdapat 12 nilai-nilai kehidupan yang tumbuh dikelas IV saat proses pembelajaran IPA berlangsung.

Tabel 1. 12 Nilai Kehidupan Kelas

\begin{tabular}{|ll|}
\hline \multicolumn{1}{|c|}{ NILAI } & \multicolumn{2}{c|}{ SUASANA KELAS } \\
\hline Kedamaian & $\begin{array}{l}\text { Suasana kelas yang } \\
\text { damai }\end{array}$ \\
\hline Penghargaan & $\begin{array}{l}\text { Memberikan } \\
\text { penghargaan atas } \\
\text { hasil karya siswa }\end{array}$ \\
\hline Cinta & $\begin{array}{l}\text { Berempati kepada } \\
\text { sesama teman }\end{array}$ \\
\hline Toleransi & $\begin{array}{l}\text { Bekerja dalam } \\
\text { kelompok yang beda }\end{array}$ \\
\hline Kejujuran & Larangan menyontek \\
\hline Kerendahan hati & $\begin{array}{l}\text { Guru terbuka } \\
\text { menerima saran dari } \\
\text { siswa }\end{array}$ \\
\hline Kerjasama & $\begin{array}{l}\text { Pengaturan kelas } \\
\text { yang meudahkan } \\
\text { interaksi siswa }\end{array}$ \\
\hline Kebahagiaan & $\begin{array}{l}\text { Pembelajaran } \\
\text { diselingi ice breaking }\end{array}$ \\
\hline
\end{tabular}




\section{Oleh: Suci Muzfirah dan Muqowim}

\begin{tabular}{|llr|}
\hline Tanggung jawab & $\begin{array}{l}\text { Peran serta aktif } \\
\text { dalam kegiatan } \\
\text { sekolah }\end{array}$ \\
\hline Kesederhanaan & Tidak sombong \\
\hline Kebebasan & $\begin{array}{l}\text { Suasana kelas } \\
\text { demokratis }\end{array}$ \\
\hline Persatuan & $\begin{array}{l}\text { Menjaga keutuhan } \\
\text { kelas }\end{array}$ \\
\hline
\end{tabular}

Menurut Ibu Uliyah Hidayah selaku walikelas di kelas IV MI Tunas Cendekia, penguatan karakter pada siswa di usia dasar memiliki peranan yang sangat penting untuk menjadikan siswa memiliki akhlak yang baik. Living Values Education program khususnya pada ranah keislaman juga sangat penting untuk diberikan kepada siswa.

Pada nilai kedamaian, guru dan peserta didik membentuk suasana kelas yang tenang, membiasakan sikap warga kelas yang anti kekerasan, dan kekerabatan dikelas yang penuh kasih sayang. Jika dalam melaksanakan kegiatan berkelompok dalam proses pembelajaran IPA, lalu ada siswa yang melakukan hal tidak baik seperti mengucapkan sesuatu yang dapat menyebabkan siswa lainnya merasa mereka tidak senang dan tidak nyaman atas kehadiran siswa tersebut sebagai anggota kelompok, maka hal yang harus dilakukan oleh gutu adalah menerapkan aturan-aturan dalam berkelompok. Memberikan pemahaman kepada ketua kelompok agar dapat memimpin jalannya diskusi dengan cara menerima setiap saran dari anggota kelompok dan menghargai pendapat teman yang lainnya.

Pada nilai penghargaan, guru wajib memberikan reward atas hasil karya yang dibuat oleh peserta didik, dengan memajang tanda penghargaan prestasi peserta didik dengan memberikan bintang di masing-masing nama peserta didik, serta membangun suasana pembelajaran yang bertujuan untuk memotivasi peserta didik agar mampu bersaing dengan sehat dan berprestasi. Khususnya dalam pembelajaran IPA, yang dilakukan

sebagai guru dalam menyikapi perbuatan serta tindakan siswanya yang dapat memotivasi siswa lain untuk dapat berguna bagi orang disekitarnya adalah dengan memberikan reward, selain itu bagi yang belum mendapatkan reward maka guru harus menjelaskan bahwa harus lebih rajin lagi dalam belaajr dan mampu mengerjakan tugas dengan baik dan yang bekerja keras saat melakukan eksplorasi dalam pembelajaran IPA.

Pada nilai cinta, guru harus menciptakan rasa empati kepada siswa agar peserta didik mampu berempati kepada sesama teman kelas, melakukan pembelajaran aksi sosial, serta menciptakan rasa saling menyayangi dan berbagi. Tentunya sebagai pengajar, hal yang wajib diperhatikan pada peserta didik ketika pembelajaran dimulai adalah dengan memberikan sikap teladan kepada siswa dengan mencontohkannya dikehidupan nyata, sehingga siswa akan memiliki tingkah laku serta perbuatan yang dapat memberikan rasa ingin sekali memberikan bantuan kepada orang lain yang sedang membutuhkan di lingkungan masyarakat.

Pada nilai toleransi, guru harus memberikan pelayanan yang sama terhadap seluruh warga kelas tanpa membedakan suku, ras, agama, golongan, status sosial dan status ekomomi, bekerja dalam kelompok yang berbeda. Saat proses pembelajaran IPA dimulai, lalu ada siswa yang berbeda pendapat dalam menyikapi suatu hal/fenomena yang sedang dijelaskan oleh guru, maka guru memberikan kesempatan kepada semua siswa dalam memberikan pendapat dan meng-hargainya. Setelah 
itu, maka guru meluruskan suatu hal tersebut dan menjelaskannya pada siswa.

Pada nilai kejujuran, guru dan siswa membuat tempat temuan barang yang hilang atau telah menemukan barang milik siswa yang lain, menyediakan tempat pengumaman barang yang hilang, menanamkan rasa transparansi dengan melaporkan keuangan serta penilaian-penilai kelas secara berkelanjutan, dan adanya larangan saling menyontek bagi siswa. Dalam hal ini, saat proses latihan soal maupun ulangan soal IPA guru memberikan kepercayaan yang tinggi pada siswa bahwa siswa tidak akan saling menyontek dan tentunya memberikan semangat dan dukungan.

Pada nilai kerendahan hati, guru harus menciptakan suasana bersaing secara sehat dalam mencapai prestasi, siswa yang berprestasi mau berbgai pengetahuan kepada siswa lain, siswa yang mengalami kesulitan mau belajar kepada siswa yang sudah memahami, guru terbuka menerima saran dari siswa, dan siswa terbuka menerima saran dari siswa lainnya.

Pada nilai kerjasama, guru membuat pengaturan kelas yang dapat memudahkan siswa dalam melakukan interaksi, pembelajara dalam kelompok, dan dalam berkomunikasi, guru tidak menjaga jarak dengan siswa. Saat proses pembelajaran IPA, jika ada siswa A yang tidak ingin berkelompok dengan siswa B dan malah ingin memilih sendiri tanpa adanya musyawarah, maka yang harus dilakukan oleh guru adalah menanyakan alasan terlebih dahulu mengapa siswa A tidak mau berkelompok dengan siswa $\mathrm{B}$ dan memberikan solusi dengan masalah tersebut.

Pada nilai kebahagiaan, pengaturan kelas yangaktif, kreatif dan menyenangkan bagi siswa, saat proses pembelajaran diselingi game menyenangkan (ice breaking), dan penampilan guru yang menyenangkan bagi siswa. Saat proses pembelajaran IPA, agar dapat menciptakan pembelajaran IPA yang menyenangkan dan tidak membuat siswa merasa bosan

maka guru harus memiliki inovasi dan kreativitas, tidak lupa juga dengan menggunakan metode dan media yang tepat guna dan tepat sasaran serta semenarik mungkin. Tidak lupa juga untuk memberikan ice breaking di selasela proses pembelajaran.

Pada nilai tanggung jawab, siswa dapat melaksanakan tugas piket secara teratur, peran aktif siswa dalam kegiatan sekolah, mengerjakan tugas tepat waktu, dan mengerjakan tugas sesuai dengan perannya di dalam kelompok. Dalam pembelajaran IPA kelas 4 di MI Tunas Cendekia terdapat salah satu tugas untuk membuat sebuah kincir angin. Keesokan harinya, guru menyuruh seluruh siswa untuk mengumpulkan tugas tersebut. Saat hendak dikumpulkan, ada siswa yang membuatnya dengan mengeluarkan berbagai alasan. Jika ada masalah tersebut, maka guru harus perduli dengan siswa tersebut dengan memberikan kesempatan kedua dengan memberikan batas waktu untuk siswa tersebut mengerjakan. Tentunya untuk score akan berbeda dengan siswa yang telah mengerjakan tugas tersebut dirumah.

Pada nilai kesederhanaan, siswa diajarkan untuk berhemat dalam menggunakan fasilitas belajar di kelas seperti penggunaan listrik dan peralatan sekolah, tidak berlebihan dan menyombongkan diri, dan juga tidak membawa peralatan mewah seperti handphone, gadget, perhiasan yang berlebihan, dan lainnya. Adapun pembelajaran IPA pastinya sangat membutuhkan fasilitas sekolah seperti 
media pembelajaran. Menjadi seorang guru harus memiliki inovasi dan kreatifitas tinggi dalam merancang pembelajaran. Guru bisa menggunakan media pembelajaran yang konkrit/ nyata seperti tanaman di halaman sekolah dan lainnya, dan membuat media pem-belajaran yang sederhana jika sekolah belum mampu untuk membeli media yang lebih bagus.

Pada nilai kebebasan, guru harus bisa menciptakan kelas demokratis, guru memberikan kesempatan kepada siswa untuk mengemukakan pendapat secara bebas dan bertanggung jawab, dan siswa berani mengemukakan pendapat. Apalagi pada pembelajaran IPA di kelas IV ini, ada beberapa siswa yang bertanya dan tentunya mengemukakan pendapatnya terhadap materi yang sedang ia pelajari. Maka guru wajib mendengarkan dan menghargai pendapat siswa. Setelah itu, meluruskan yang benar seperti apa kepada seluruh siswa dikelas.

Pada nilai persatuan, tiap siswa harus menjaga keutuhan kelas, menghindari pengelompokkan siswa berdasarkan ras, agama, suku dan antar golongan, mampu menjaga nama baik kelas, dan mengutamakan kepentingan kelas daripada individu atau kelompok tertentu. Tentunya untuk membangun nilai persatuan siswa di kelas IV pada pembelajaran IPA adalah dengan membuat sebuah permainan edukasi dengan berkelompok, dan juga membuat simulasi mengenai persatuan yang bisa disesuaikan dengan pembelajaran IPA sesuai dengan materi yang dibahas.

Pentingnya penanaman karakter bagi siswa usia sekolah dasar dapat dilakukan dengan menggunakan living values education. Lickona juga menambahkan tentang pentingnya pendidikan karakter yang memuat tujuan yang mulia. Menurutnya, pendidikan karakter dan pendidikan moral bukanlah sebuah ide baru. Hal tersebut, pada kenyataannya, semua pendidikan itu memuat pendidikan karakter dan moral. Sepanjang sejarah, di negaranegara di seluruh dunia, pendidikan telah memiliki dua tujuan besar yaitu membantu anak-anak muda menjadi cerdas dan untuk membantu mereka menjadi manusia yang lebih baik serta berguna bagi sesama dan masyarakat luas $^{13}$.

\section{Pembahasan}

\section{Pentingnya Living Values Education (LVE) bagi Siswa MI Tunas Cendekia}

Menurut walikelas IV di MI Tunas Cendekia, penanaman nilai-nilai karakter yang dapat diterapkan pada proses belajar mengajar menggunakan living values education adalah rasa ingin tahu, kerja keras, demokratis, mandiri, menghargai prestasi, benari/kritis, kreatif, logis dan peduli lingkungan. Saat merefleksi pembelajaran, cara untuk mengintegrasikan nilai-nilai dalam kehidupan nyata yakni dengan memberikan contoh yang baik dalam kehidupan bermasyarakat dan tidak lupa juga untuk membuat daftar ceklis siswa sebagai hasil refleksi yang memuat nilai-nilai living values education agar guru mengetahui perkembangan karakter siswa mengenai nilai-nilai kehidupan yang mungkin sebelumnya telah tertanam pada diri peserta didik.

Adapun agar proses pengintegrasian living values education (LVE) dalam proses dari belajar mengajar dapat berjalan dengan lancar,

\footnotetext{
13 ‘PENGARUH LIVING VALUES EDUCATION PROGRAM (LVEP) TERHADAP PENANAMAN KARAKTER NASIONALISME SISWA SD DALAM PEMBELAJARAN TEMATIK | Apriani | Taman Cendekia: Jurnal Pendidikan Ke-SD-An', n.d., h. 103.,

https://jurnal.ustjogja.ac.id/index.php/tamancend ekia/article/view/1947/1129.
}

el Bidayah: Journal of Islamic Elementary Education Volume 3, Nomor 1, Maret 2021 
maka sebagai seorang pengajar sekaligus pendidik tentunya harus dapat memasukkan nilai kebudayaan lokal, menggunakan metode dan media pembelajaran yang variatif. Dengan mengenalkan budaya lokal, maka siswa akan secara langsung memahami nilainilai kehidupan yang ada disekitarnya sesuai dengan tujuan pembelajaran yang dilaksanakan. Begitu pula dengan metode dan media pembelajaran yang inovatif serta variative sehingga akan membuat siswa merasa tidak jenuh dalam belajar sehingga proses integrasi LVE diharapkan dapat berjalan lancer dan sesuai dengan tujuan pembelajaran. Menurut penelitian yang dilakukan oleh Makhfud dan Ali Imron, metode yang dapat dilakukan agar pembelajaran menjadi bermakna adalah menggunakan metode pembelajaran Snowball Throwing. Dimana efektifitas metode pembelajaran tersebut dapat meningkatkan keberhasilan peserta didik dalam belajar, dapat membuat proses belajar mengajar menjadi lebih menye-nangkan, dapat meningkatkan minat belajar dan motivasi yang tinggi untuk belajar serta dapat membuat peserta didik terlibat aktif dalam proses pembelajaran dikleas khususnya pada pembelajaran IPA $^{14}$. Sehingga proses pembelajaran IPA akan menjadi bermakna dan dapat memasukkan nilai-nilai kehidupan (LVE).

Karena MI Tunas Cendekia merupakan sekolah yang bernuansa islami, maka pengintegrasian keislaman berbasis living values education dengan ilmu pendidikan juga tidak kalah pentingnya. Jenjang pendidikan pada

\footnotetext{
14 'Efektifitas Metode Pembelajaran Snowball Throwing Pada Mata Pelajaran IPA Kelas V SDIT Al Azhar Kota Kediri', n.d., h. 20-22, https://ejournal.iaitribakti.ac.id/index.php/pgmi/article/view/1335/7
} 65.
SD/MI menerapkan pembelajaran tematik dimana model pembelajaran tersebut dapat memudahkan proses integrasi islam dengan ilmu pendidikan. Pendidik ditingkat SD/MI bisa memulai integrasi islami berbasis living values education dengan mengembangkan bahan dan materi ajar pada jenjang sekolah dasar baik SD/MI yang selama ini terpisahkan antara pembelajaran keagamaan dengan pembelajaran formal lainnya ${ }^{15}$. Dalam hal ini Yusuf menjelaskan bahwa tujuan umum pendidikan Islam adalah bahwa kompetensi yang sangat diharapkan oleh Islam yang dimiliki oleh seluruh peserta didik selesainya melalui proses pembelajaran ialah kompetensi al-infi'al - al-insani al-ilahi (afektif manusiawi sebagai hamba Tuhan), yakni kesadaran eksklusif akan keberadaan Tuhan serta tertanam keyakinan pada jiwanya, bahwa tidak ada kenyataan kehidupan ini yang tak bersumber dari Allah ${ }^{16}$.

\section{Upaya Pengintegrasian Living Values Education (LVE) dalam Proses Pembelajaran IPA Siswa Kelas IV} Pengintegrasian living values education (LVE) dengan proses pembelajaran IPA dalam konteks keislaman dapat dilihat konsep integrasi islam dan sains. kata integrasi Islam dan Sains dipahami sebagai upaya mempertemukan, memadukan atau menjalin kemitraan antara ilmu serta kepercayaan pada upaya mensejajarkan ilmu dan agama. Konsep tersebut mencoba menyampaikan porsi yang sama antara sains atau ilmu dengan kepercayaan

\footnotetext{
${ }^{15}$ Muhammad Munadi, 'Integrasi Islam Dan IImu Dalam Praktek Di Lembaga Pendidikan', IAN SURAKARTA, 7 January 2016, https://iainsurakarta.ac.id/integrasi-islam-dan-ilmu-dalampraktek-di-lembaga-pendidikan/.

${ }^{16}$ Kadar M.Yusuf, Tafsir Tarbawi : Pesan-Pesan AlQur'an Tentang Pendidikan, 1st ed. (Jakarta: Amzah, 2015), 89.
} 
Islam dengan berlandaskan nilai-nilai universalitas Islam, yaitu bersumber pada ayat qauliyah (dibaca: al-Qur'an dan hadis) dan ayat kauniyah (kenyataan alam). Keterpaduan antara urusan duniawi serta ukhrowi, jasmani serta rohani, material serta spiritual menjadi satu kesatuan yang sama-sama bersumber dari Tuhan. Didalam proses pembelajaran IPA, pembelajaran yang wajib dipusatkan kepada peserta didik (student centerd), oleh karena itu hakikat peserta didik (the nature of the learner) perlu dipahami terlebih dahulu. Hal ini berdampak pada pengajar dalam melaksanakan proses belajar mengajar, seorang pengajar harus dapat berbuat sinkron dengan kondisi peserta didiknya yang mencakup kondisi psycho-physic (jiwa-raga) ${ }^{17}$. Dengan mengetahui kondisi peserta didik, maka proses pengintegrasian living values education dalam pembelajaran IPA akan berjalan sebagaimana yang diharapkan.

Upaya-upaya yang dilakukan oleh pendidik untuk menjadikan nilainilai luhur agama itu sebagai bagian dari diri peserta didik pada forum pendidikan formal perlu dilakukan secara sistematis dan terpadu oleh seluruh unsur pendidikan yang ada di lembaga pendidikan seperti di SD/MI. Upayaupaya yang dilakukan ialah dengan membentuk pergaulan yang bersifat mendidik, keteladanan yang mencerminkan sikap serta tingkah laku yang bisa dihayati baik secara individual maupun secara bersama-sama. Tentunya peserta didik juga diajak mengamalkan dengan berbagai cara seperti melakukan kegiatan yang dapat

\footnotetext{
${ }^{17}$ Fauzan Fauzan, 'Integrasi Islam Dan Sains Dalam Kurikulum Program Studi Pendidikan Guru MI Berbasis KKNI', JMIE: Journal of Madrasah Ibtidaiyah Education, 2017, h. 7. 42
}

meningkatkan nilai kehidupan islami peserta didik $^{18}$.

Pentingnya pengintegrasian nilai-nilai Islam pada pembelajaran IPA menjadi satu kerangka normatif pada merumuskan tujuan pendidikan sebagaimana diungkapkan oleh Ali dan Luluk bahwa tujuan penanaman nilainilai Islam, yaitu: pertama, menyebarkan wawasan spiritual yang semakin mendalam dan mengembangkan pemahaman rasional.

Perihal Islam dalam konteks kehidupan terutama yang berkaitan dengan ayat-ayat kauniyah (alam). Kedua, membekali peserta didik dengan banyak sekali macam kemampuan pengetahuan alam. Ketiga, mengembangkan kemampuan pada diri peserta didik untuk menghargai dan membenarkan superioritas komparatif khazanah pengetahuan Islam di atas seluruh khazanah pengetahuan yang lain. Keempat, memperbaiki dorongan emosi melalui pengalaman imajinatif, sehingga kemampuan kreatif dapat berkembang dan berfungsi mengetahui tata cara-tata cara Islam yang benar serta yang keliru. Kelima, membantu anak yang sedang tumbuh untuk belajar berpikir secara logis serta membimbing proses pemikirannya dengan berpijak pada hipotesis dan konsep-konsep pengetahuan alam yang dituntut. Perkembangan living values education berbasis keislaman sangat penting diterapkan kepada siswa dalam semua pembelajaran, khususnya pembelajaran IPA. Perkembangan living values education perlu ditingkatkan lagi agar penerapannya sesuai dan menghasilkan anak-anak / siswa yang bukan hanya pintar dalam bidang akademis, tetapi juga memiliki nilai-nilai kehidupan

\footnotetext{
${ }^{18}$ Fuad Ihsan, Dasa-Dasar Kependidikan : Komponen MKDK (Jakarta: PT. Rineka Cipta, 2013), h. 161.

el Bidayah: Journal of Islamic Elementary Education Volume 3, Nomor 1, Maret 2021
} 
Vpaya Pengintegrasian Living Values Education (LVE) dalam Proses Pembelajaran IPA Siswa Kelas IV di MI Tunas Cendekia Cirebon

Oleh: Suci Muzfirah dan Muqowim

sehingga kehidupannya akan selalu bermakna.

\section{Kesimpulan}

Salah satu cara menjadikan proses pembelajaran khususnya pada pembelajaran IPA menjadi sangat bermakna yakni dengan meng-integrasikan living values education. Seperti halnya yang dila-kukan oleh guru kelas IV di MI Tunas

Cendekia Kabupaten Cirebon dalam mengupayakan pengintegrasian living values education pada proses pembelajaran IPA siswa kelas IV. Hasilnya, terdapat 12 nilai-nilai kehidupan dan nilai keislaman yang dapat diintegrasikan dengan proses pembelajaran IPA. Dengan mengintegrasikan living values education pada siswa, maka peserta didik berhasil tidak hanya pada bidang kognitif saja, akan tetapi juga pada pengembangan nilai-nilai karakter serta living values education.

\section{Daftar Pustaka}

Arafik, Muh. 'Living Values Educational Program: Children Literature Instruction to Improve Character Values of Elementary School Students': In Proceedings of the 1 St International Conference on Information Technology and Education (ICITE 2020). Malang, Indonesia: Atlantis Press, 2020. https://doi.org/10.2991/assehr. k.201214.241.

'Arofah, Fajrul. 'PEMBELAJARAN IPA DAN IPS BERBASIS INTEGRASI DAN INTERKONEKSI DENGAN PAI (STUDI KASUS DI MIN MLANGEN SALAMAN DAN MI MA"ARIF KEBONSARI
BOROBUDUR KABUPATEN MAGELANG TAHUN PELAJARAN 2013/2014)'. IAIN SALATIGA, 2015.

'Efektifitas Metode Pembelajaran Snowball Throwing Pada Mata Pelajaran IPA Kelas V SDIT Al Azhar Kota Kediri', n.d. https://ejournal.iaitribakti.ac.id/index.php/pgmi/a rticle/view/1335/765.

Fauzan, Fauzan. 'Integrasi Islam Dan Sains Dalam Kurikulum Program Studi Pendidikan Guru MI Berbasis KKNI'. JMIE: Journal of Madrasah Ibtidaiyah Education, 2017.

Ihsan, Fuad. Dasa-Dasar Kependidikan : Komponen MKDK. Jakarta: PT. Rineka Cipta, 2013.

Komalasari kokom, saprudin didin. Bandung: PT. Refika Aditama, 2017.

Munadi, Muhammad. 'Integrasi Islam Dan Ilmu Dalam Praktek Di Lembaga Pendidikan'. IAN SURAKARTA, 7 January 2016. https://iainsurakarta.ac.id/integrasi-islamdan-ilmu-dalam-praktek-dilembaga-pendidikan/.

M.Yusuf, Kadar. Tafsir Tarbawi : PesanPesan Al-Qur'an Tentang Pendidikan. 1st ed. Jakarta: Amzah, 2015.

Novianti. 'INTEGRASI NILAI-NILAI ISLAM DALAM PEMBELAJARAN IPA DI SEKOLAH | Muspiroh | QUALITY', 2014.

https://journal.iainkudus.ac.id/i ndex.php/Quality/article/view/ 2099/1737.

Nufus, Hayati. 'PEMBINAAN KARAKTER MAHASISWA BERBASIS LIVING VALUES EDUCATION'. al-Iltizam: Jurnal Pendidikan Agama Islam 4, no. 1 (30 May 2019): 148. 
Upaya Pengintegrasian Living Values Education (LVE) dalam Proses Pembelajaran IPA Siswa Kelas IV di MI Tunas Cendekia Cirebon

Oleh: Suci Muzfirah dan Muqowim

https://doi.org/10.33477/alt.v4 i1.758.

'Pembiasaan Keterampilan Berpikir Kritis Sebagai Sarana Implementasi Sikap Spiritual Dalam Pembelajaran IPA Tingkat Sekolah Dasar | Kamala | AlBidayah: Jurnal Pendidikan Dasar Islam', n.d. https://jurnal.albidayah.id/inde x.php/home/article/view/187/ 173.

'PENGARUH LIVING VALUES EDUCATION PROGRAM (LVEP) TERHADAP PENANAMAN KARAKTER NASIONALISME SISWA SD DALAM PEMBELAJARAN TEMATIK | Apriani | Taman Cendekia: Jurnal Pendidikan Ke-SD-An', n.d.

https://jurnal.ustjogja.ac.id/inde x.php/tamancendekia/article/vi ew/1947/1129.

'PENGEMBANGAN MEDIA

PEMBELAJARAN IPA BERBASIS

ANDROID UNTUK SISWA SD/MI

| Prasetyo | JMIE (Journal of Madrasah Ibtidaiyah Education)', n.d. https://ejournal.adpgmiindonesia.com/in dex.php/jmie/article/view/29/ 9.

Sarah, S, Z K Prasetyo, and I Wilujeng. 'Integration of Living Values into Physics Learning Based on Local Potentials'. Journal of Physics: Conference Series 1022 (May 2018): 012026.

https://doi.org/10.1088/17426596/1022/1/012026.

Sulistiowati, Rahayu, Eko Budi Sulistio, and Ita Prihantika. 'PELATIHAN PENDIDIKAN INTEGRITAS UNTUK GURU SMP MELALUI METODE LIVING VALUES EDUCATION (LVE) DI KECAMATAN LUMBOK
SEMINUNG, KABUPATEN LAMPUNG BARAT', n.d., 7. Wahidin, Wahidin. Metode Pendidikan Ilmu Pengetahuan Alam. Bandung: Sangga Buana, 2006. widi, eka sulistyowati wisudawati asih. Metodologi Pembelajaran IPA. Jakarta: Bumi Aksara, 2015. 